\title{
METHODS FOR IMPROVING ALPHA-MANGOSTIN SOLUBILITY: A REVIEW
}

\author{
NURUL FAJERIYATII,3, MUCHTARIDI MUCHTARIDI ${ }^{1}{ }^{*}$, IYAN SOPYAN ${ }^{2}$ \\ ${ }^{1}$ Department of Pharmaceutical Analysis and Medicinal Chemistry, Faculty of Pharmacy, Padjadjaran University, Sumedang, Indonesia, \\ ${ }^{2}$ Department of Pharmaceutics and Pharmaceutical Technology, Faculty of Pharmacy, Padjdjaran University, Sumedang, Indonesia, \\ ${ }^{3}$ Faculty of Pharmacy, University of Muhammadiyah Banjarmasin, Banjarmasin, Indonesia \\ Email: muchtaridi@unpad.ac.id
}

Received: 16 Jul 2020, Revised and Accepted: 07 May 2021

\begin{abstract}
Solubility is an important parameter to achieve for the bioavailability of a drug to reach the therapeutic windows. Garcinia mangostana Linn is a plant with great potency for the development of natural medicine. Alpha-mangostin is one of the secondary metabolites of $G$. mangostana and has been reported to have several pharmacological activities. The Biopharmaceutics Classification System (BCS) is a system that classifies drugs based on their solubility and permeability. Due to its low solubility but high permeation, alpha-mangostin is categorized into class II of the Biopharmaceutics Classification System. Therefore, the determination of dosage forms and modification of solubility enhancers is limited due to its physical properties, as mentioned above. This disadvantage requires new methods to improve its solubility to administer alpha-mangostin, especially for oral administration. Here, we discuss the development of the methods to increase alpha-mangostin solubility to be applied to formulate a dosage form to reach a useful plasma level for medication.
\end{abstract}

Keywords: Alpha-mangostin, Solubility, Drug delivery system

(C) 2021 The Authors. Published by Innovare Academic Sciences Pvt Ltd. This is an open access article under the CC BY license (https://creativecommons.org/licenses/by/4.0/) DOI: https://dx.doi.org/10.22159/ijap.2021v13i4.39065. Journal homepage: https://innovareacademics.in/journals/index.php/ijap

\section{INTRODUCTION}

Solubility is the maximum amount of a compound to be dissolved in a specific solvent at equilibrium. The solubility of a compound increases with the increasing temperature of the solution [1]. In the pharmaceutical setting, the solubility of a drug is an important parameter to achieve the expected concentration, since to be able to reach the useful plasma level, a drug needs to be dissolved in a specific solvent (which must be a non-toxic solvent) at a certain concentration. By knowing the solubility of a drug, it is easier to formulate its dosage form. A proper-formulated dosage form guarantees that molecules of a drug reach its target site resulting in bioavailability. As a result, a specific therapeutic effect is the manifestation of the bioavailability of the drug [2].

Garcinia mangostana Linn is widely known in Indonesia as having the potency to be developed as natural medicine. Among the secondary metabolites of G. mangostana Linn, alpha-mangostin has been identified as its major xanthone [3]. Alpha-mangostin is extracted from $G$. mangostana with methanol, followed by purification using chromatographic techniques [4]. In general, xanthone is a group of oxygenated heterocyclic compounds which have extraordinary pharmacological activities and have been reported to have multiple pharmacological effects [5]. Specifically, alpha-mangostin has been reported to have several pharmacological effects such as anticancer [6, 7], cardioprotective [8], anti-inflammatory [9], anti-acne [10], anti-TBC [11], antioxidant [12], antibacterial [13], Recurrent Aphthous Stomatitis (RAS) [14], and antifungal [15]. Based on the aforementioned reports, many pharmaceutical industries are now trying to develop and sell various alpha-mangostin containing products (nutraceuticals, functional foods, food supplements, and medicinal products) as promotive, preventive or curative agents for a particular disease [16].

Alpha-mangostin belongs to the xanthone group, which has hydrophobic properties, and is therefore classified into class II of the Biopharmaceutics Classification System (BCS) due to its low solubility but high permeability. It is not soluble in water resulting in difficulties in determining a dosage form, especially for oral administration [17]. Therefore, the solubility of alpha-mangostin needs to be improved to be able to formulate it into an oral dosage form, in order that its bioavailability in the gastrointestinal and intestinal fluids can be achieved [18].

In this review, we discuss the techniques that have been carried out to increase the solubility of alpha-mangostin. This review is based on a literature study of the reports obtained from Scopus, Google Scholar, ScienceDirect, Springer, and PubChem databases that have been published in the last $15 \mathrm{y}$, by using specific keywords "solubility", "alpha-mangostin", and "drug delivery system". To obtained reliable reports, we applied the following inclusion criteria (articles and reviews) and exclusion criteria (opinions and material by the topic).

\section{Solubility and influencing factors}

The solubility of a compound is dependent on the structure and condition of the solution. The structure of a compound determines its polarity and hydrogen bonds determine the solubility of a compound in a solution. The condition of the solution is influenced by $\mathrm{pH}$, co-solvent, and temperature [19]. Solubility is also influenced by the nature of the compound and the solvent, particle size, molecular size, molecular structure and pressure [20].

Several factors influence the solubility of a compound. The first factor affecting solubility is polarity, the ability of compounds to form poles. By nature, non-polar compounds dissolve in non-polar solvents, and polar compounds are dissolved in polar solvents. The second factor is hydrogen bonding, an interaction that occurs between the hydrogen bonding donor group and the atoms, which have strong electronegativities such as the halogen, oxygen, and nitrogen groups. Hydrogen atoms form bonds with electronegative atoms based on electrostatic properties and build hydrogen bridges. Hydrogen bonds can occur intramolecular or intermolecular [21]. The third factor is $\mathrm{pH}$, the solubility depends on the $\mathrm{pH}$ that will be used [22]. Where an increase in the $\mathrm{pH}$ of the alpha-mangostin microgel mixture can cause a decrease in particle size from $548 \mathrm{~nm}$ to $200 \mathrm{~nm}$. Alpha-mangostin at low $\mathrm{pH}$ shows the shape of the crystals, but with an increase in $\mathrm{pH}$ around $\mathrm{pH} \mathrm{6}$, its physical shape changes [4]. Solubility depends on the $\mathrm{pH}$ used [22]. The fourth factor is the co-solvent, whose usage in a solution can change the solubility of organic compounds. Co-solvent can increase the solubility of non-polar drugs because it has a small hydrocarbon area. The addition of co-solvent can reduce the interaction between solvents, which leads to a decrease in surface tension and dielectric constant [21]. The fifth factor is temperature, which affects solubility. The solubility will increase due to the increase of temperature in an absorbing energy process. Conversely, in the process of releasing energy, the solubility will decrease due to the decreasing temperature [23]. Generally, an increase in temperature will increase the size of micelles, thereby increasing solubility [20]. 
The sixth factor is the nature of solutes and solvents, which depend on the concentration of the solute in the solvent to be used, for example, 100 grams of water can only dissolve 1 gram of $\mathrm{Pb}^{2+}[20]$. The seventh factor is particle size; if the particle size decreases, the surface area to volume ratio increases. When the surface area of the particles increases, it will cause a greater interaction with the solvent, and in consequence, the solubility will increase. This basic principle is explained in the equation below [24].

$$
\log \frac{S}{\text { So }}=\frac{2 \gamma \mathrm{V}}{2.303 \text { R.T.r }}
$$

Where so $=$ the solubility of large particles, $\mathrm{S}=$ the solubility of fine particles, $\mathrm{V}=$ molar volume, $\gamma=$ the surface tension of solid objects, and $r=$ the radius of fine particles.

The eighth factor is the molecular size and molecular structure. The solubility of a substance will decrease if it has a higher molecular weight because larger molecules are difficult to be surrounded with solvent molecules to dissolve substances [24]. If there is a change in molecular structure it will result in a change in solubility [25]. The ninth factor is pressure; for solid and liquid solutes, solubility is not affected by pressure changes, but for the gas solutes, the solubility will increase with increasing pressure and decrease if pressure is lowered [20].

The techniques to increase the solubility of a compound can be grouped into physical modification, chemical modification, and other techniques. Physical modifications are techniques to change the physical aspects of the compound such as a reduction in particle size (micronization and nanosuspension), crystal modification (polymorph, amorphous, and cocrystal form), solid dispersion, and cryogenic techniques. Chemical modifications deal with the chemical property of the compound, such as changes in $\mathrm{pH}$, using buffer solutions, replacing with derivatives, forming complex compounds, and using the nature of the salt. Other methods such as supercritical fluid processes, the use of auxiliaries such as surfactants, solvents, co-solvent, hydrography, and new excipients can also be used to increase the solubility [18].

\section{Biopharmaceutics classification system (BCS)}

The solubility and permeability characteristics of a substance are classified into four categories according to the Biopharmaceutics Classification System (BCS), which can be seen in fig. 1. BCS is one of the prognostics to facilitate the development of oral preparations in recent years and to establish bioavailability standards [26].

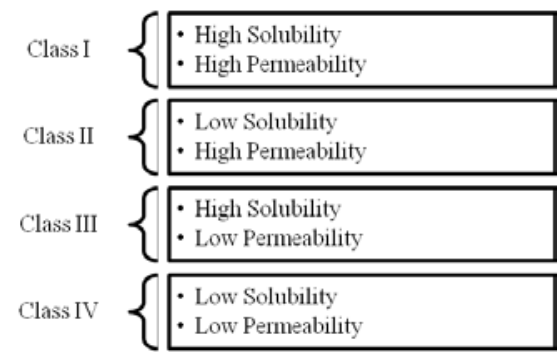

Fig. 1: Biopharmaceutics classification system (BCS)

Class II drugs have high permeation values but are low in dissolution rates. With the low dissolution, the value will be a limitation of the bioavailability of a drug [27]. More than $70 \%$ of newly discovered compounds fall into the BCS class II category [28]. One of the natural compounds that is categorized into the class II BCS is alphamangostin isolated from mangosteen peel extract [29]. The solubility of alpha-mangostin is $2.03 \times 10^{-4} \mathrm{mg} / \mathrm{ml}$ in the water at $25{ }^{\circ} \mathrm{C}$ [30]. The solubility of an acceptable compound for a drug is $>60 \mu \mathrm{g} / \mathrm{ml}$ [17]. Study of pharmacokinetic profiles in vivo shows the limited levels of alpha-mangostin in plasma [31].

Table 1: The properties of alpha-mangostin

\begin{tabular}{|c|c|c|}
\hline Property & Description & References \\
\hline $\begin{array}{l}\text { Structure } \\
\text { Chemical names } \\
\text { Molecular formula } \\
\text { Molecular weight } \\
\text { Physical state } \\
\text { Color/form } \\
\text { Melting point } \\
\text { Solubility } \\
\text { Dissociation constants }\end{array}$ & $\begin{array}{l}\text { 1,3,6-trihydroxy-7-methoxy-2,8-bis(3-methylbut-2-enyl)xanthen-9-one } \\
\text { Solid } \\
\text { Faint yellow to yellow powder } \\
180-181{ }^{\circ} \mathrm{C} \\
\text { In water } 2.03 \text { x } 10^{-4} \mathrm{mg} / \mathrm{ml} \text { at } 25^{\circ} \mathrm{C} \\
\text { Soluble in methanol } \\
\text { pKa } 1=3,68 \text { (primary carbonyl) } \\
\text { pKa } 2=7,69 \text { (secondary carbonyl) } \\
\text { pKa } 3=9,06 \text { (tertiary carbonyl) }\end{array}$ & [30] \\
\hline
\end{tabular}

The techniques used to improve the solubility of drugs of class II BCS are grouped into three major groups, namely traditional techniques, newer and novel techniques, and solid dispersion techniques. Traditional techniques consist of the use of solvent, hydrotropy, using dielectric constant solvents, amorphous formation, chemical modification of drugs, use of surfactants, the formation of inclusion complexes, solvent $\mathrm{pH}$ regulation, use of hydrates or solvents, use of ultrasonic waves, functional polymer technology, pre-precipitation, and evaporation. Newer and novel techniques consist of technology size reduction, nanoparticles, porous nanoparticles, nanocrystals, nanosuspensions, microemulsions, micellar, cryogenic technology, supercritical, lipid-based delivery systems, self-dispersing lipid formulations, micelle blends, and micelle polymers. Solid dispersion techniques consist of amorphous deposition of the crystalline carrier, continuous solid solution, discontinuous solid solution, substitutional solid solution, interstitial solid solution, glass suspension, and glass solution [23].

Several techniques have been carried out to increase the solubility of alpha-mangostin, as presented in table 2 .

\section{Nanoparticle technology}

The technology of nanoparticles in nanomedicine has an important role in clinical therapy. Because of the size of the particles from $10^{-9}$ $\mathrm{m}$ causes the surface area of the nanoparticles to increase the contact surface with the solvent. The increase of surface area correlates with the increase of the rate of dissolution and absorption of drugs into the body [44]. To overcome the low solubility of an 
active ingredient in water, both the active ingredient and the excipient can be reduced into nanosize [45]. The use of nanoparticle techniques can also increase permeation which leads to an increase in oral bioavailability [46]. The formation of nano-or microparticles is strongly influenced by the type and the concentration of the polymer to be used [47]. The use of cellulose derivative polymers forms a nano reservoir in the nanoparticle technique [48]. The use of chitosan polymeric nanoparticles can improve the physicochemical properties and performance of alpha mangostin [49], and in combination with eudragit S 100 [50]. The addition of co-solvents or surfactants to the formula affects the solubility and dissolution of cellulose [51].

Table 2: Techniques to increase the solubility of alpha-mangostin

\begin{tabular}{|c|c|c|c|}
\hline Technique & Excipient & Result & References \\
\hline $\begin{array}{l}\text { Nanoparticles (nanocarrier, } \\
\text { encapsulation) }\end{array}$ & Ethylcellulose: Methylcellulose (1:1) & Increased activity & {$[32,33]$} \\
\hline Nanoparticles (nanocarrier) & Proniosome & Increased permeation & {$[34]$} \\
\hline Nanoparticles (nano micelles) & $\begin{array}{l}\text { MPEG-PCL (Monomethoxy Poly Ethylene Glycol- } \\
\text { PolyCaproLactones) }\end{array}$ & Increased solubility and activity & [35] \\
\hline Nanoparticles (nanofiber) & Chitosan thiolated and polyvinylalcohol & Increased solubility & [36] \\
\hline Self Microemulsion (SME) & Isopropyl myristate, Tween 80, PEG-400 & Increased Area Under Curve & [37] \\
\hline Size reduction & Sodium lauryl sulfate and poloxamer 188 & Particle size reduction & [38] \\
\hline $\begin{array}{l}\text { Solid dispersion, Amorphous } \\
\text { formation }\end{array}$ & Polyvinilpirolidon & Increased solubility & [17] \\
\hline Amorphous formation & PLGA (Poly Lactic-co-Glycolic Acid) & Increased solubility & [39] \\
\hline Drug carrier & Rice husk silica & Increased solubility & [40] \\
\hline Solid dispersion & Vegetable oil & Increased bioavailability & [16] \\
\hline Complex formation & Beta cyclodextrin & Increased solubility & {$[41,42]$} \\
\hline SNEDDS & Virgin Coconut Oil (VCO), tween 80, PEG 400 & Increased permeation & [43] \\
\hline
\end{tabular}

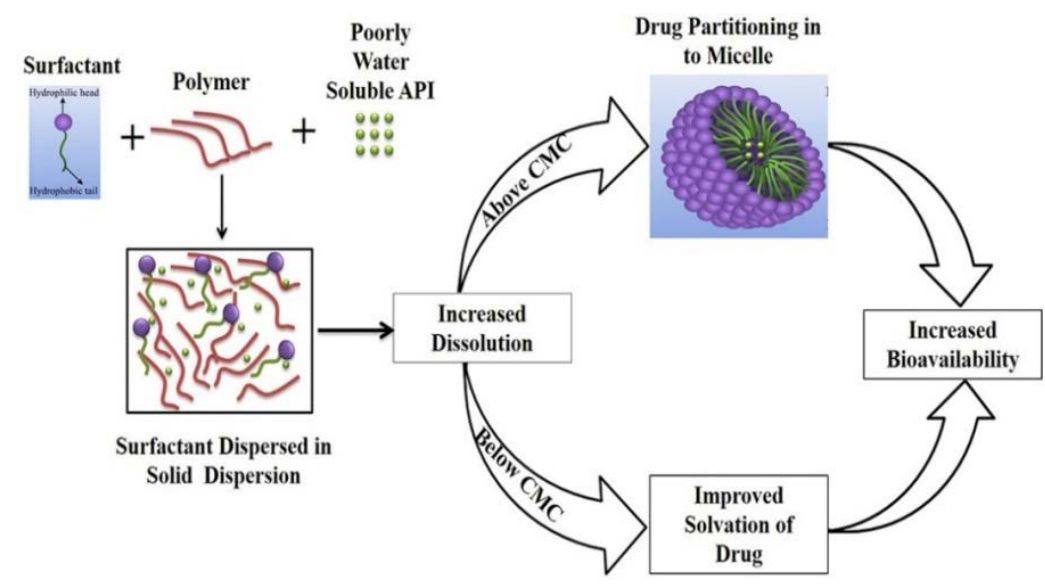

Fig. 2: Mechanisms of adding surfactants and polymers to solid dispersions to increase the bioavailability of a drug [52]

Alpha-mangostin, which is used for the treatment of $H$. pylori infections, is prepared with an encapsulation technique with a stable mucoadhesive nanocarrier in an acid solution. Ethylcellulose and methylcellulose (1:1) are used as a nanocarrier through self-assembly techniques [32]. The selection of polymers is very important, as the branched polymers are more soluble than non-branched (linear) polymers despite having the same molecular weight because the carbon chain is a hydrophobic group [53]. Here, cellulose derivatives are used as polymers in the process of forming encapsulation [54].

This encapsulation technique has been shown to have better cellular absorption and anticancer activity than non-encapsulated alphamangostin [33]. The use of cellulose derivates is to absorb large amounts of water, due to its large surface area, high porosity, and low fragility [55]. Cellulose also has an affinity in the formation of complexes with drugs and can reduce the crystallization of drugs in forming an amorphous matrix [56], and in doing so, demonstrates the efficacy of the treatment in mice after oral administration.

Proniosome (spans, soy lecithin, and cholesterol) can be used as an alternative nanocarrier. These compounds can increase the permeation of alpha-mangostin up to 1.8 to 8 times by using the coacervation method [34]. In another example, the formation of alpha-mangostin nano micelles produced a stronger effect on antimelanoma when compared to free alpha-mangostin, making it suitable for use as a chemotherapy agent [35].

\section{Self-microemulsion (SME)}

Alpha-mangostin is loaded into self-microemulsion (SME). The results showed that this technique could increase the area under the curve (AUC) of alpha-mangostin by 4.75 times and the increase in distribution to the lymphatic organs. SME in nanosize is an efficient delivery system to increase the absorption, which will ultimately increase the bioavailability of alpha-mangostin [37]. This drug delivery system can help solve problems related to drug delivery that is difficult to dissolve [57].

\section{Snedds}

SNEDDS (self-nano-emulsifying drug delivery system) is defined as an isotropic mixture of oil, surfactant, and co-solvent, cosurfactant, or hydrophilic co-solvent. It has a particle size of less than $100 \mathrm{~nm}$ [58]. After the addition of isotropic mixture, it will interact with the fluids of the digestive tract and form an oil nanoemulsion in water. The formation of nanoemulsion will dissolve the drugs in small drops of oil, thereby expanding the surface area, which facilitates the release and absorption of the drug [59]. Illustration of SNEDDS formation can be seen in fig. 6 .

The SNEDDS mechanism increases the solubility and bioavailability of drugs. If lipids enter the channel area in the Gastro Intestinal it will cause contraction of the gallbladder, which eventually stimulates the secretion of the bile duct and pancreas. Due to the contractions, 
SNEDDS will create a coarse emulsion that increases the dissolution of hydrophobic drugs. Lipids also cause delays in the emptying of the stomach, so the hydrophobic drug transit time slightly increases. In the end, the drug dissolution improves and the absorption increases [60].

The SNEDDS method produces small round particles with oxidative stability and that are free-flowing, so they can be developed as solid dosage forms [61]. SNEDDS is also a promising carrier because it improves the bioavailability and therapeutic effects of the class II BCS drugs [62]. And solubility of drugs that are lipophilic [63]. SNEDDS improve the dissolution and increase intestinal permeation. As a result, the efficacy of orally administered drugs increases [64]. A report showed SNEDDS could increase the diffusion rate of mangosteen peel, taking into account the solubility of the active component in oil, surfactants, and co-solvent to obtain optimal formulation [43]

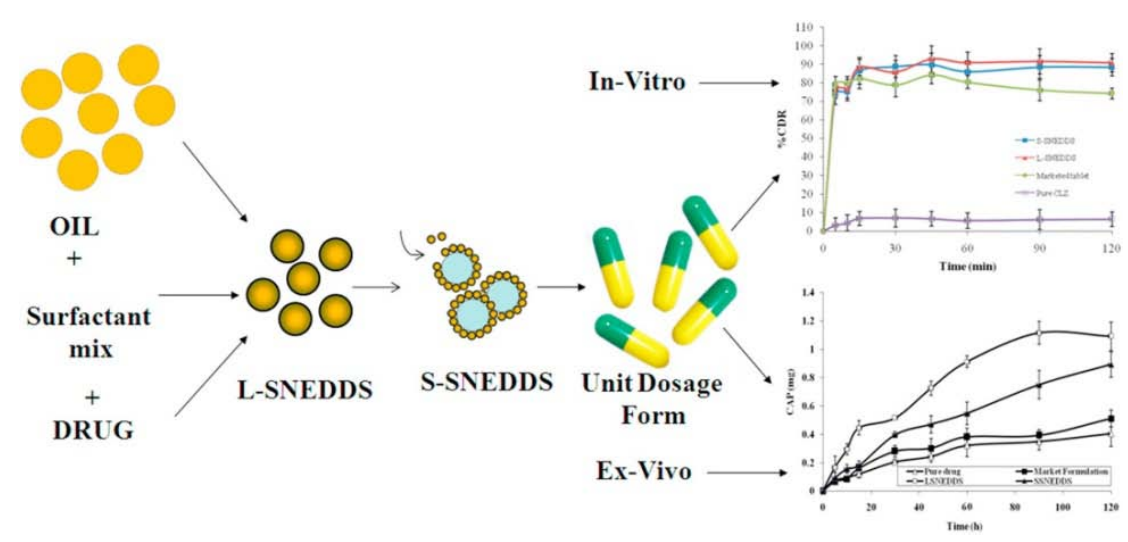

Fig. 3: Illustration of self-nano-emulsifying drug delivery system (SNEDDS) formation [65]

\section{Size reduction}

The size reduction of alpha-mangostin using high-pressure homogenization (HPH) with the addition of stabilizers turns out to be effective. The efficiency of reducing the size of alpha-mangostin suspension particles significantly decreases to them micron size by using sodium lauryl sulfate stabilizer and poloxamer 188 [38]. HPH has a principle of cavitation in the aqueous phase. The cavitation force in a particle is high enough to turn microparticles into nanoparticles [18].

\section{Amorphous formation}

The amorphous form is an irregular shape of a molecule with a higher energy level than a crystal. In the digestive tract, the amorphous form will cause a higher concentration gradient and cause an increase of permeation through the intestinal membrane [28]. Amorphous formation by using a solid matrix can increase the dissolution, solubility, and bioavailability of a drug, as the amorphous phase has a weak lattice that causes the contact and wetting process of the solvent [66]. The free energy, enthalpy, and entropy produced by amorphous solids are also relatively high when compared to crystalline shapes due to the irregular structure of amorphous solids [67]. Although sometimes amorphous formation is still constrained in terms of stability, the addition of a stabilizer can increase the stability of the amorphous form [68].

The physical changes in crystal alpha-mangostin to amorphous form increase solubility from the original $0.2 \pm 0.02 \mathrm{~g} / \mathrm{ml}$ can be increased to $2743 \pm 11 \mathrm{~g} / \mathrm{ml}$ [17]. The microencapsulation of alpha-mangostin can also change the crystalline form of alpha-mangostin to an amorphous form, which improves its water solubility. As a result, the bioavailability of the drug increases [39]. The use of rice husk silica as the carrier of alphamangostin, via the sol-gel method, has been investigated and showed the changing of the crystal form of alpha-mangostin into amorphous form, increasing the solubility of alpha-mangostin [40].

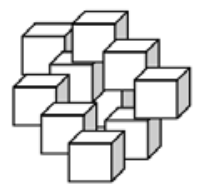

Crystall

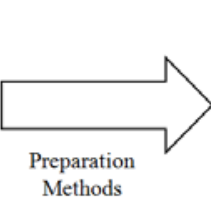

Methods

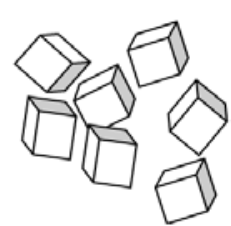

Amorphous
Fig. 4: Crystal and amorphous shapes

\section{Solid dispersion}

Solid dispersion is a dispersion technique of one or more active substances into a matrix, or an inert carrier in a solid state. Principles to reduce particle size, better wetting processes, and reducing agglomeration can produce a high concentration of a drug in the gastrointestinal fluids, which will increase the solubility and bioavailability of the drug [69]. Solid dispersions usually have two different components, usually, the matrix is hydrophilic, while the drug or API is hydrophobic. The matrix used can be either a crystal matrix or an amorphous shape matrix [70]. The addition of surfactants in solid dispersions is needed to reduce recrystallization to increase dissolution and stability [52].

Solid dispersion systems have an advantage over other systems for increasing oral bioavailability without changing active targets. It is achieved by forming salts or incorporating polar or ionized group compounds into the structure of the drugs [71]. Solid dispersions are made by various methods, as shown in fig. 4 .

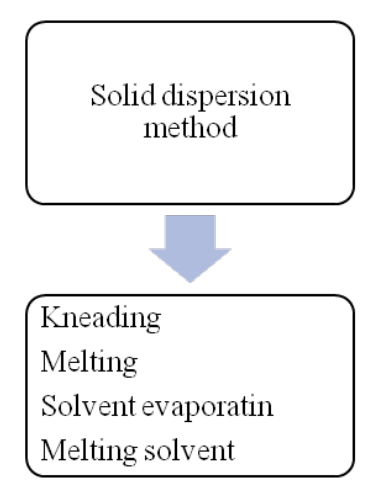

Fig. 5: Solid dispersion method [72]

Solid dispersion technique is applied to alpha-mangostin using a solvent evaporation method, with the formation of a complex between alpha-mangostin and PVP (polyvinylpyrrolidone), to produce alpha-mangostin with increased solubility [17]. PVP is used as a matrix because PVP is a non-toxic substance, has very soluble properties in the water, is inert, and thermostable [73]. PVP also has a small size to increase the wet ability and solubility of a drug [72]. 
Soft capsules containing alpha-mangostin with vegetable oil as a matrix also can improve the bioavailability of alpha-mangostin. The distribution of alpha-mangostin can be detected in the brain which means alpha-mangostin can cross the blood-brain barrier after oral administration [16].

\section{Complex formation}

Chemical modification by forming a complex between alphamangostin and quaternate beta-cyclodextrin combined can increase the solubility of alpha-mangostin [41]. Cyclodextrin is a cyclic oligosaccharide that can form non-covalent bonds with several drugs so that it does not change the physicochemical properties of the drug. The primary and secondary hydroxyl cycle of cyclodextrin is a potential site for the modification of a drug [74]. An illustration of cyclodextrin complex formation with drugs can be seen in fig. 5 . Cyclodextrin is a carrier of drugs that are non-toxic and biodegradable [75]. Complex formation with cyclodextrin is also preferable because of the increase of free energy $(\Delta G)$ and complex energy $(\Delta E)[76]$. The beta-cyclodextrin bond with alpha-mangostin produces about 14 hydrogen bonds [77]. Beta cyclodextrin will attach to the nanoparticle conjugate, which will be positively charged by the ionic bond [78]. Beta cyclodextrin has 2 derivatives of 2.6 dimethyl- $\square$ cyclodextrin and 2-hydroxypropyl- $\square$ cyclodextrin, which are commonly used to form inclusion complexes with alphamangostin. 2-hydroxypropyl- $\square$ cyclodextrin is able to bind with alpha mangostin to form complex bonds in hydrogel formulation [79]. The results showed 2.6 dimethyl- $\square$ cyclodextrin results in a more soluble complex than 2-hydroxypropyl- $\square$ cyclodextrin [42]. The formation of a complex with cyclodextrin usually uses two methods, namely the solvent evaporation and kneading methods, but the solvent evaporation technique showed significant improvement on the drug's release and solubility [80].

\section{The use of surfactants}

The use of surfactants increases the dissolution of compounds in water. Surfactants increase the dissolution of lipophilic drugs in aqueous media and reduce surface tension. When the surfactant exceeds the critical micelle concentration, micelle formation occurs trapping the compounds in the micelle (micellization process), which increases the solubility of the compounds. Surfactants also increase the wetting of solids, thereby increasing the rate of disintegration into finer particles [18]

Various methods have been used to increase the solubility of alphamangostin as previously described. The results of these various methods were certainly characterized to ensure that there was indeed an increase in the solubility of alpha-mangostin. Characterization was carried out such as FT-IR spectra examination (fig. 7) which showed that there was vibrational streaching of alpha mangostin on the hydroxyl groups that appeared at 3416.1 and $3251.7 \mathrm{~cm}-1$. In the solid dispersion of alpha mangostin mangostin (SDs), the bands at 3416.1 and $3251.7 \mathrm{~cm}-1$ and at 1608.8, 1049.9, 1009.8, 849, 812.4, and 782.7 $\mathrm{cm}-1$ disappeared. The stretching of the PVP carbonyl groups appeared at $1646.5 \mathrm{~cm}-1$ indicating there was a redshift to a mean of $1649 \pm 0.8 \mathrm{~cm}-1$ in SDs. These results indicate the participation of the $\mathrm{OH}$ group in alpha mangostin in the interaction of the hydrogen bond with the PVP carbonyl group. On the other hand, the peak position of the $\mathrm{OH}$ alpha mangostin group in and the physical mixture alpha mangostin (PMs) slightly changed [17].

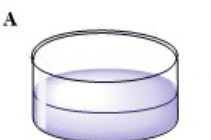

CD

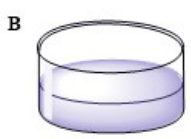

CD

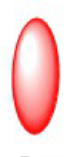

Drug

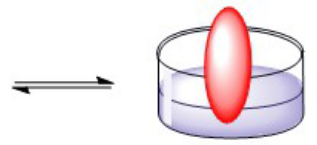

1:1 Drug-CD Complex

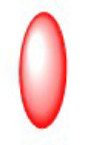

Drug

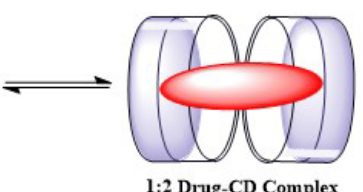

1:2 Drug-CD Complex
Fig. 6: Illustration of cyclodextrin complex formation with drugs [81]

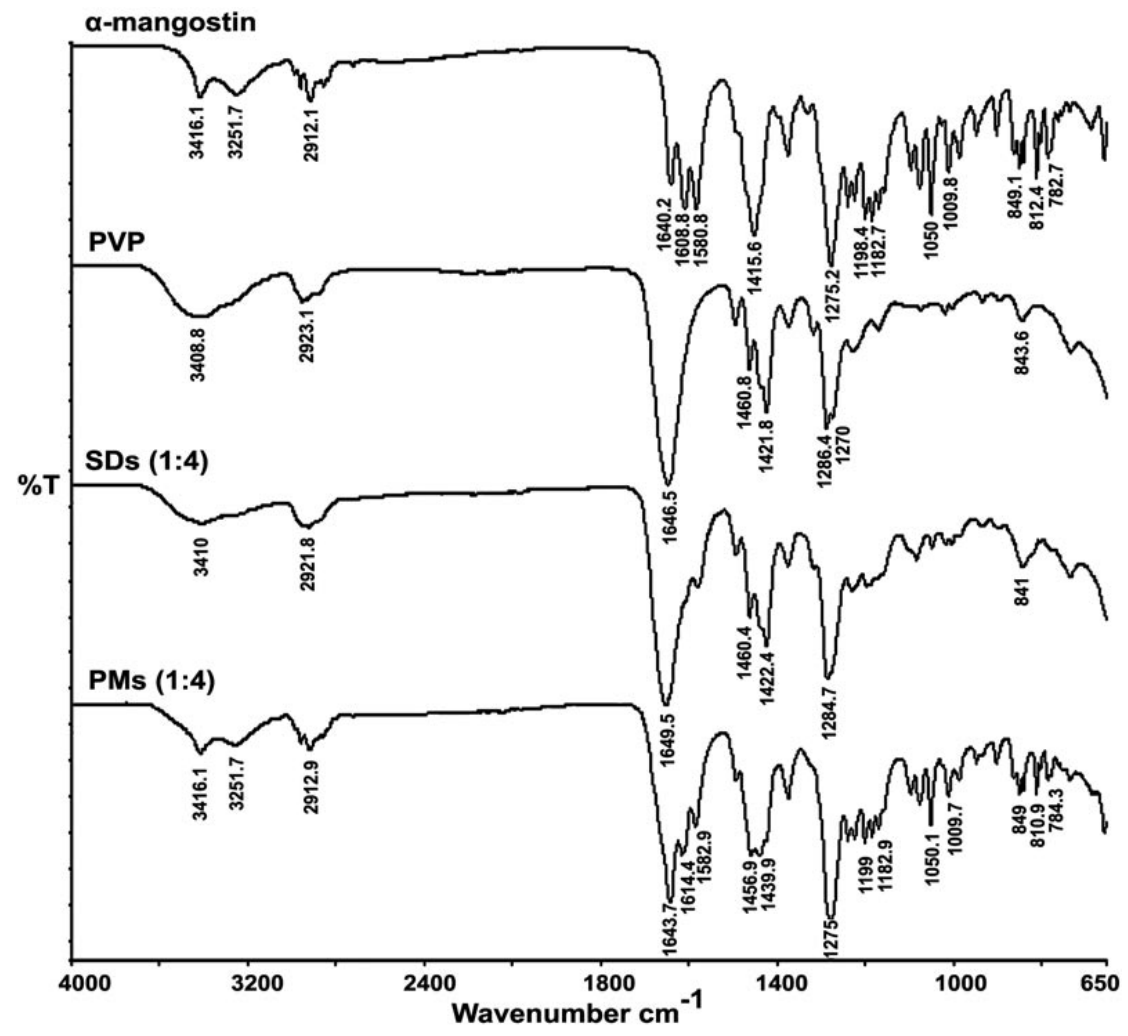

Fig. 7: FT-IR spectrum [17] 
Characterization using Differential scanning calorimetry (DSC) of alpha mangostin, PVP, solid dispersion alpha mangostin (SDs) and physical mixture alpha mangostin (PMs) is illustrated in fig. 8. Alpha Mangostin produces sharp endothermic peaks at $180^{\circ} \mathrm{C}$ according to

(a)

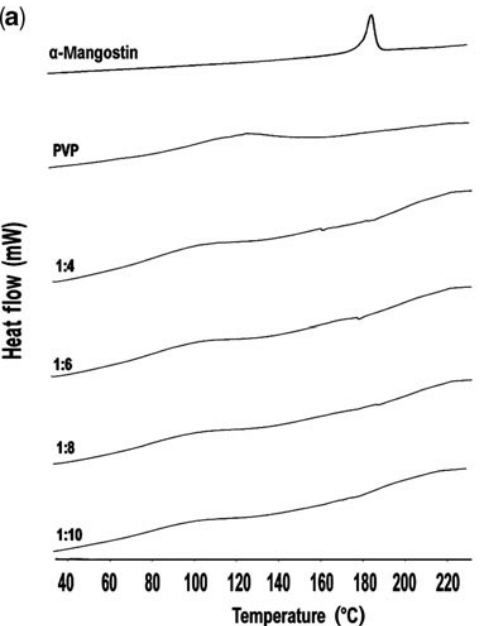

its melting point, while PVP shows wide peaks in the temperature range of $100{ }^{\circ} \mathrm{C}-160{ }^{\circ} \mathrm{C}$. The endothermic peaks of alpha mangostin disappeared in all SDs and PMs, indicating an interaction between alpha mangostin and PVP [17]. (b)

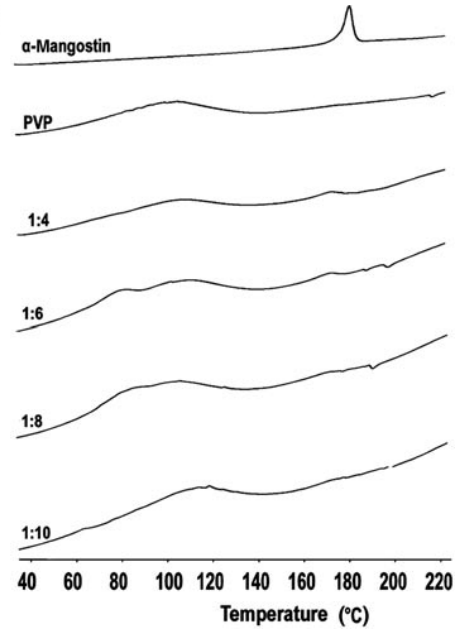

Fig. 8: Differential scanning calorimetry thermograms of (a) "-mangostin solid dispersions and (b) physical mixtures [17]

Characterization of powder XRD pattern showed alpha mangostin peaks appeared at the diffraction angle of $2 \theta$ at $15.9^{\circ}, 18.2^{\circ}, 20^{\circ}$, $23.3^{\circ}, 26^{\circ}, 30.6^{\circ}$, and $32.2^{\circ}$ (fig. 9) indicating that alpha mangostin was present in crystalline form. PVP (K29/32) is an amorphous powder and does not show any peaks. The SD diffraction pattern showed loss of alpha-mangostin crystal peaks, indicating that alpha-mangostin was converted from crystals to amorphous forms. This results in an interaction between alpha-mangostin and PVP and may help explain the increase in solubility of the compound [17].

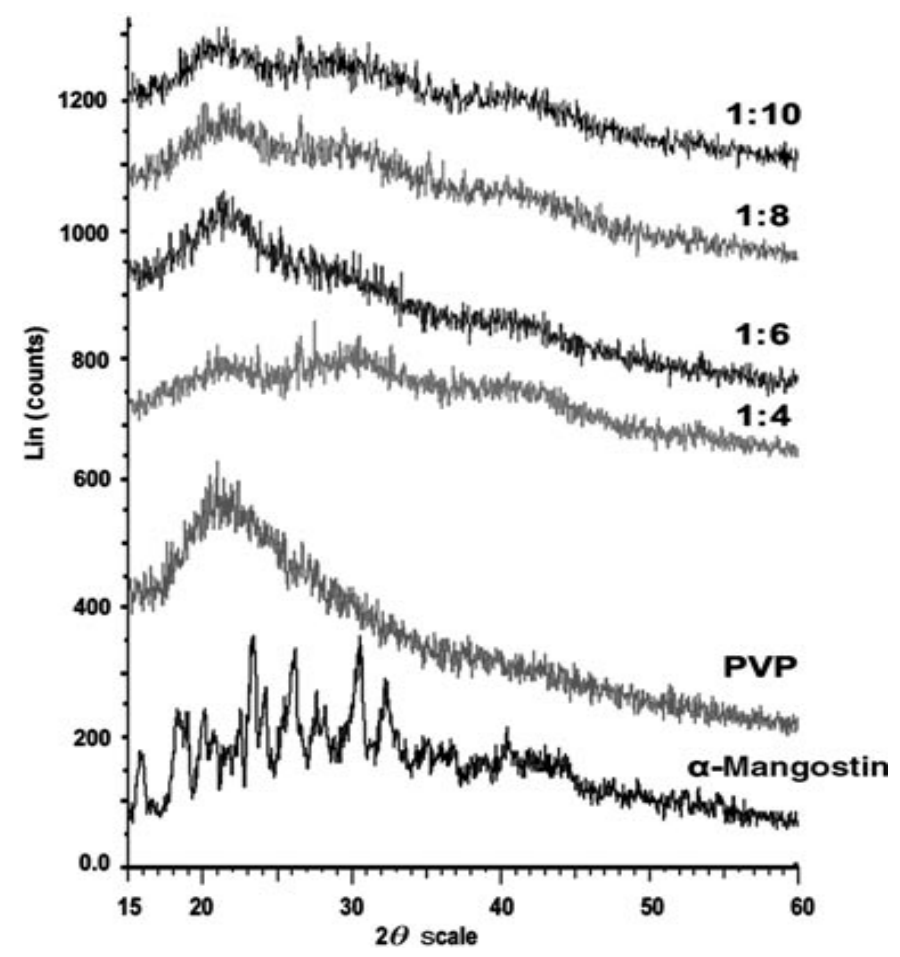

Fig. 9: X-ray diffraction patterns of alpha-mangostin solid dispersions [17]

\section{CONCLUSION}

Alpha-mangostin has been known to have low solubility, correlated with its low bioavailability in the blood. However, alpha-mangostin has many pharmacological activities, therefore, various techniques are needed to increase the solubility of alpha-mangostin. Currently, many techniques have been developed to increase the solubility of alphamangostin through physical modifications such as a reduction in particle size (nanoparticle technology), amorphous formation, solid dispersion, and chemical modification, such as the formation of complex compounds by adding surfactants and co-solvent. Among the various techniques, nanoparticle technology is most widely used to 
increase the solubility of the alpha-mangostin because it has many ways and mechanisms to increase solubility. Among them, as previously discussed, the reduction in particle size in nanotechnology increases the solubility of drugs by means of expanding the surface area of the particles. The use of water-soluble (hydrophilic) excipients as a component of nanoparticles increases the solubility of the drug due to the hydrogen bonding interaction between the excipient used and water molecules. The use of surfactants also increases the solubility of drugs with high lipophilicity properties through reduced interfacial tension in nanotechnology.

\section{FUNDING}

Nil

\section{AUTHORS CONTRIBUTIONS}

All authors have contributed equally.

\section{CONFLICT OF INTERESTS}

Declare none

\section{REFERENCES}

1. Rohn J. Pharmacokinetics and preformulation; 2017. p. 17-37.

2. Vemula VR, Lagishetty V, Lingala S. Solubility enhancement techniques. Int J Pharm Sci Rev Res 2010;5:41-51.

3. Schimid DW. Ueber Mangostin; 1849. p. 83-8.

4. Ahmad M, Yamin BM, Lazim AM. A study on dispersion and characterization of $\alpha$-mangostin loaded $\mathrm{pH}$ sensitive microgel systems. Chem Central J 2013;85:2-7.

5. Aisha AFA, Malik A, Abdulmajid S, Ismail Z, Alrokayan SA, Abusalah KM. Development of polymeric nanoparticles of garcinia mangostana xanthones in eudragit RL100/RS100 for anti-colon cancer drug delivery. J Nanomaterials 2015;7:1-12.

6. Fei X, Jo M, Lee B, Han SB, Lee K, Jung JK, et al. Synthesis of xanthone derivatives based on $\alpha$-mangostin and their biological evaluation for anti-cancer agents. Bioorg Med Chem Lett 2014;24:2062-5.

7. Muchtaridi M, Wijaya CA. Anticancer potential of alphamangostin. Asian J Pharm Clin Res 2017;10:440-5.

8. Sampath PD, Vijayaraghavan K. Cardioprotective effect of $\alpha$ mangostin, a xanthone derivative from mangosteen on tissue defense system against isoproterenol-inducedmyocardial infarction in rats. J Biochem Mol Toxicol 2007;21:336-9.

9. Chen LG, Yang LL, Wang CC. Anti-inflammatory activity of mangostins from garcinia mangostana. Food Chem Toxicol 2008;46:688-93.

10. Pothitirat W, Chomnawang MT, Supabphol R, Gritsanapan W. Comparison of bioactive compounds content, free radical scavenging and anti-acne inducing bacteria activities of extracts from the mangosteen fruit rind at two stages of maturity. Fitoterapia 2009;80:442-7.

11. Sudta P, Jiarawapi P, Suksamrarn A, Hongmanee P, Suksamrarn S. Potent activity against multidrug-resistant mycobacterium tuberculosis of $\alpha$-mangostin analogs. Chem Pharm Bull 2013;61:194-203.

12. Jung HA, Su BN, Keller WJ, Mehta RG, Kinghorn AD. Antioxidant xanthones from the pericarp of garcinia mangostana (mangosteen). J Agric Food Chem 2006;54:2077-82.

13. Koh JJ, Qiu S, Zou H, Lakshminarayanan R, Li J, Zhou X, et al. Rapid bactericidal action of alpha-mangostin against MRSA as an outcome of membrane targeting. Biochim Biophys Acta 2013;1828:834-44.

14. Wathoni N, Yuniarsih N, Cahyanto A, Muhctaridi M. Amangostin hydrogel film based chitosan-alginate for recurrent aphthous stomatitis. Appl Sci 2019;9:1-14.

15. Kaomongkolgit R, Jamdee $\mathrm{K}$, Chaisomboon N. Antifungal activity of alpha-mangostin against Candida albicans. J Oral Sci 2009;51:401-6.

16. Zhao Y, Tang G, Tang Q, Zhang J, Hou Y, Cai E, et al. A method of effectively improved $\alpha$-mangostin bioavailability. Eur J Drug Metab Pharmacokinet 2016;41:605-13.

17. Aisha AFA, Ismail Z, Abu-Salah KM, Majid AMSA. Solid dispersions of $\alpha$-mangostin improve its aqueous solubility through selfassembly of nanomicelles. J Pharm Sci 2011;101:815-25.
18. Savjani KT, Gajjar AK, Savjani JK. Drug solubility: importance and enhancement techniques. ISRN Pharm 2012;1-10. DOI: $10.5402 / 2012 / 195727$.

19. Kerns E, Di L, Carter G. In vitro solubility assays in drug discovery. Curr Drug Metab 2008;9:879-85.

20. Kasimedua S, Thoppani SR, Pommalab N, Orugonda G, Yelamanda J. A review on solubility enhancement techniques. J Compr Pharm 2015;2:36-41.

21. Mantri RV, Sanghvi R, Zhu HJ. Solubility of pharmaceutical solids. Developing solid oral dosage forms: pharmaceutical theory and practice: $2^{\text {nd }}$ Edition. Elsevier Inc; 2017. p. 3-22.

22. Patil SS, Ram Mohan Gupta V, Srikanth Gupta K, Doddayya H. Effect of ph, selected cyclodextrins and complexation methods on the solubility of lornoxicam. Int J Pharm Pharm Sci 2014;6:324-7.

23. Kansara H, Panola R, Mishra A. Techniques used to enhance the bioavailability of bcs class II drugs: a review. Int J Drug Dev Res 2015;7:82-93.

24. Chaudhary A, Nagaich U, Gulati N, Sharma V, Khosa R, Partapur M. Enhancement of solubilization and bioavailability of poorly soluble drugs by physical and chemical modifications: a recent review. J Adv Pharm Educ Res 2012;2:32-67.

25. Sanjaymitra P, Ganesh G. Dissolution and solubility enhancement strategies: current and novel prospectives. J Crit Rev 2018;5:1-10.

26. Dahan A, Miller JM, Amidon GL. Prediction of solubility and permeability class membership: provisional BCS classification of the world's top oral drugs. AAPS J 2009;11:740-6.

27. Yasir M, Asif M, Kumar A, Aggarval A. Biopharmaceutical classification system: an account. Int J PharmTech Res 2010;2:1681-90.

28. Vermeersdch $H$. Solubility and permeation studies using soluplus $\AA$ and hpmc with a bcs class ii amorphous drug. J Pharm Res Int 2016;18:1-40.

29. Li L, Brunner I, Han AR, Hamburger M, Kinghorn AD, Frye R, et al. Pharmacokinetics of $\alpha$-mangostin in rats after intravenous and oral application. Mol Nutr Food Res 2011;55 Suppl 1:67-74.

30. Alpha mangostin. Available from: https://pubchem.ncbi.nlm.nih.gov/compound/alphaMangostin. [Last accessed on 10 Jul 2020]

31. Ramaiya A, Li G, M Petiwala S, J Johnson J. Single-dose oral pharmacokinetic profile of $\alpha$-mangostin in mice. Curr Drug Targets 2012;13:1698-704.

32. Pan-In P, Tachapruetinun A, Chaichanawongsaroj N, Banlunara W, Suksamrarn S, Wanichwecharungruang S. Combating helicobacter pylori infections with mucoadhesive nanoparticles loaded with garcinia mangostana extract. Nanomedicine 2014;9:457-68.

33. Pan-In P, Wanichwecharungruang S, Hanes J, Kim AJ. Cellular trafficking and anticancer activity of garcinia mangostana extract-encapsulated polymeric nanoparticles. Int J Nanomed 2014;9:3677-86.

34. Chin GS, Todo H, Kadhum WR, Hamid MA, Sugibayashi K. In vitro permeation and skin retention of $\alpha$ mangostin proniosome. pdf. Chem Pharm Bull 2016;64:1666-73.

35. Yang S, Gao X, He Y, Hu Y, Xu B, Cheng Z, et al. Applying an innovative biodegradable self-assembly nanomicelles to deliver $\alpha$ mangostin for improving anti-melanoma activity. Cell Death Disease 2019;10:146.

36. Samprasit W, Rojanarata $\mathrm{T}$, Akkaramongkolporn $\mathrm{P}$, Ngawhirunpat T, Kaomongkolgit R, Opanasopit P. Fabrication and in vitro in vivo performance of mucoadhesive electrospun nanofiber mats containing $\alpha$ mangostin. AAPS PharmSciTech 2015;16:1-13.

37. Xu WK, Jiang H, Yang K, Wang YQ, Zhang Q, Zuo J. Development and in vivo evaluation of self-microemulsion as the delivery system for $\alpha$-mangostin. Kaohsiung J Med Sci 2017;33:116-23.

38. Limwikrant W, Aung T, Chooluck K, Puttipipatkhachorn S, Yamamoto K. Size reduction efficiency of alpha-mangostin suspension using high-pressure homogenization. Chem Pharm Bull 2019;67:389-92.

39. Elsaid Ali AA, Taher M, Mohamed F. Microencapsulation of alpha-mangostin into PLGA microspheres and optimization using response surface methodology intended for pulmonary delivery. J Microencapsul 2013;30:728-40. 
40. Iqbal A, Muhammad Shuib NA, Darnis DS, Miskam M, Abdul Rahman NR, Adam F. Synthesis and characterisation of rice husk ash silica drug carrier for $\alpha$-mangostin. J Phys Sci 2018;29:95-107.

41. Phunpee S, Suktham K, Surassmo S, Jarussophon S, Rungnim C, Soottitantawat A, et al. Controllable encapsulation of $\alpha$ mangostin with quaternized $\beta$-cyclodextrin grafted chitosan using high shear mixing. Int J Pharm 2018;538:21-9.

42. Hotarat W, Phunpee S, Rungnim C, Wolschann P, Kungwan N, Ruktanonchai $\mathrm{U}$, et al. Encapsulation of alpha-mangostin and hydrophilic beta-cyclodextrins revealed by all-atom molecular dynamics simulations. J Mol Liq 2019;288:110965.

43. Liza P, Fudholi A, Martien R, Pramono S. Self-nano emulsifying drug delivery system (snedds) for topical delivery of mangosteen peels (garcinia mangostana l.,): formulation design and in vitro studies. J Young Pharm 2017;9:107-14.

44. Kalepu S, Nekkanti V. Improved delivery of poorly soluble compounds using nanoparticle technology: a review. Drug Delivery Transl Res 2016;6:319-32.

45. Irving B. Nanoparticle drug delivery systems. Innovations in Pharmaceutical Technology; 2007.

46. Mishra R, Mir SR, Amin S. Polymeric nanoparticles for improved bioavailability of cilnidipine. Int J Pharm Pharm Sci 2017;9:129.

47. Bozic M, Elschner T, Tkaucic D, Bracic M, Hribernik S, Stana Kleinschek $\mathrm{K}$, et al. Effect of different surface-active polysaccharide derivatives on the formation of ethyl cellulose particles by the emulsion-solvent evaporation method. Cellulose 2018;25:6901-22.

48. Pan-in P, Wongsomboon A, Kokpol C. Depositing a-mangostin nanoparticles to sebaceous gland area for acne treatment. J Pharmacol Sci 2015;129:226-32.

49. Wathoni Nasrul, Rusdin Agus, Febriani Erma, Purnama Destiana, Daulay Wahnidar, Azhary Sundoro Y, et al. Formulation and characterization of $\alpha$-mangostin in chitosan nanoparticles coated by sodium alginate, sodium silicate, and polyethylene glycol. J Pharm Bioallied Sci 2019;11:619-27.

50. Herdiana Yedi, Handaresta Devi Fitria, Joni I Made, Wathoni Nasrul. Synthesis of nano- $\alpha$ mangostin based on chitosan and eudragit S 100. J Adv Pharm Technol Res 2020;11:95-100

51. Minnick DL, Flores RA, Destefano MR, Scurto AM. Cellulose solubility in ionic liquid mixtures: temperature, cosolvent, and antisolvent e ff ects. J Phys Chem B 2016;120:7906-19.

52. Chaudhari SP, Dugar RP. Application of surfactants in solid dispersion technology for improving solubility of poorly water soluble drugs. J Drug Delivery Sci Technol 2017:41:68-77.

53. Recharla N, Riaz M, Ko S, Park S. Novel technologies to enhance solubility of food-derived bioactive compounds: a review. J Funct Foods 2017;39:63-73.

54. Crabbe Mann M, Tsaoulidis D, Parhizkar M, Edirisinghe M. Ethyl cellulose, cellulose acetate and carboxymethyl cellulose microstructures prepared using electrohydrodynamics and green solvents. Cellulose 2018;25:1687-703.

55. Zoubari G, Ali R, Dashevskiy A. Water-soluble and-insoluble polymers as binders for pellet preparation by extrusion/spheronization. J Drug Delivery Sci Technol 2019;49:1-5.

56. Mazumder S, Dewangan AK, Pavurala N. Enhanced dissolution of poorly soluble antiviral drugs from nanoparticles of cellulose acetate based solid dispersion matrices. Asian J Pharm Sci 2017;12:532-41.

57. Anand S, Gupta R, Sk P. Self-microemulsifying drug delivery system. Asian J Pharm Clin Res 2016;9:1.

58. Tobergte DR, Curtis S. Self microemulsifying drug delivery system: a lipid based drug delivery system. J Chem Inf Model 2013;53:1689-99.

59. Nasr A, Gardouh A, Ghorab M. Novel solid self-nanoemulsifying drug delivery system (S-SNEDDS) for oral delivery of olmesartan medoxomil: Design, formulation, pharmacokinetic and bioavailability evaluation. Pharmaceutics 2016;8:20.

60. Chavda VP, Shah D. Self-emulsifying delivery systems: one step ahead in improving solubility of poorly soluble drugs. Nanostructures for Cancer Therapy. Elsevier Inc.; 2017. p. 653-718.
61. Singh H, Nathani S, Singh N, Roy P, Paul S, Sohal HS, et al. Development and characterization of solid-SNEDDS formulation of DHA using hydrophilic carrier with improved shelf life, oxidative stability and therapeutic activity. J Drug Delivery Sci Technol 2019;54:101326.

62. Chaudhary S, Aqil M, Sultana Y, Kalam MA. Selfnanoemulsifying drug delivery system of nabumetone improved its oral bioavailability and anti-inflammatory effects in rat model. J Drug Delivery Sci Technol 2019;51:736-45.

63. Talele SG, Derle DV. Solubility and thermodynamic modeling of quetiapine fumarate in self nanoemulsifying drug delivery system (SNEDDS). Int J Appl Pharm 2018;10:127-32.

64. Akhtar N, Khan RA, Mohammad SAA, Yusuf M, Singh V, Mohammad HAA, et al. Self-generating nano-emulsifying technology for alternatively-routed, bioavailability enhanced delivery, especially for anti-cancers, anti-diabetics, and miscellaneous drugs. J Drug Delivery Sci Technol 2020;1:101808.

65. Sanka K, Suda D, Bakshi V. Optimization of solid-self nanoemulsifying drug delivery system for solubility and release profile of clonazepam using simplex lattice design. J Drug Delivery Sci Technol 2016;33:114-24.

66. Zaini E, Putri VZ, Octavia MD, Ismed F. Peningkatan laju disolusi dispersi padat amorf genistein dengan PVP K-30. J Sains Farm Klin 2017;4:67.

67. Gurunath S, Pradeep Kumar S, Basavaraj NK, Patil PA. Amorphous solid dispersion method for improving oral bioavailability of poorly water-soluble drugs. J Pharm Res 2013;6:476-80.

68. Ogawa N, Hiramatsu T, Suzuki R, Okamoto R, Shibagaki K, Fujita $\mathrm{K}$, et al. Improvement in the water solubility of drugs with a solid dispersion system by spray drying and hot-melt extrusion with using the amphiphilic polyvinyl caprolactampolyvinyl acetate-polyethylene glycol graft copolymer and Dmannitol. Eur J Pharm Sci 2018;111:205-14.

69. Kumar, B. Solid dispersion-a review. PharmaTutor 2017;5:24-9.

70. Singh J, Walia M, Harikumar SL. Solubility enhancement by solid dispersion method: a review. J Drug Delivery Ther 2013;3:148-55.

71. Kaur J, Aggarwal G, Singh G, Rana AC. Improvement of drug solubilty using solid dispersion. J Pharmacol Sci 2012;4:47-53.

72. Tran P, Pyo YC, Kim DH, Lee SE, Kim JK, Park JS. Overview of the manufacturing methods of solid dispersion technology for improving the solubility of poorly water-soluble drugs and application to anticancer drugs. Pharmaceutics 2019;11:1-26.

73. Jelic D, Liavitskaya $T$, Vyazovkin $S$. Thermal stability of indomethacin increases with the amount of polyvinylpyrrolidone in solid dispersion. Thermochim Acta 2019;676:172-6.

74. Bibby DC, Davies NM, Tucker IG. Mechanisms by which cyclodextrins modify drug release from polymeric drug delivery systems. Int J Pharm 2000;197:1-11.

75. Doan VTH, Lee JH, Takahashi R, Nguyen PTM, Nguyen VAT, Pham HTT, et al. Cyclodextrin based nanoparticles encapsulating $\alpha$ mangostin and their drug release behavior. Polymer J 2019;52:1-10.

76. Dermawan D, Wathoni N, Muchtaridi M. Host guest interactions of $\alpha$ mangostin with $(\alpha, \beta, \gamma)$ cyclodextrins. pdf. J Young Pharm 2019;11:31-5.

77. Hotarat $\mathrm{W}$, Nutho B, Peter Wolschann, Rungrotmongkol $\mathrm{T}$, Hannongbua S. Delivery of alpha-mangostin using cyclodextrins through a biological membrane. Molecular 2020;25:2532.

78. Shihong Q, Granet R, Mbakidi JP, Bregier F, Pouget C, Micallef, et al. Delivery of tanshinone IIA and $\alpha$ mangostin from gold PEI cyclodextrin nanoparticle platform design for prostat cancer. Bioorganic Med Chem Lett 2016;26:2503-6.

79. Wathoni N, Sari DP, Suharyani I, Motoyama K, Mohammed AFA, Cahyanto A, et al. Enhancement of $\alpha$-mangostin wound healing ability by complexation with 2-hydroxypropyl- $\beta$-cyclodextrin in hydrogel formulation. Pharmaceuticals 2020;13:1-16.

80. Adhikar L, Semalty A, Semalty M. Binary complexes of glimepiride with $\beta$-cyclodextrin for improved solubility and drug delivery. Indian Drugs 2019;56:54-60.

81. Pranjali W Chandurkara, Tushar A Shindea, Anup M Akarteb PPR. Effect of trimethoprim inclusion complexation with cyclodextrins on its antimicrobial activity. Chem Methodol 2018;3:211-25. 